\title{
A PRINCIPLE FROM LIVER EFFECTIVE AGAINST SHOCK DUE TO BURNS ${ }^{1}$
}

\author{
By MYRON PRINZMETAL, OSCAR HECHTER, CLARA MARGOLES, \\ AND GEORGE FEIGEN \\ (From the Straus Laboratory, Cedars of Lebanon Hospital, and the University of Southern Californic \\ Medical School, Los Angeles)
}

(Received for publication October 11, 1943)

The purpose of this report is to describe a new method of evaluating therapeutic activity in shock and to present evidence for a principle in liver extract, which has the activity of significantly decreasing the mortality which follows a standardized scalding burn.

The development of new therapeutic agents useful in shock has, in large part, been impaired by the absence of standardized quantitative methods for evaluating anti-shock activity. During the past 2 years, a shock-producing procedure has been developed in this laboratory that has permitted satisfactory evaluation of antishock activity in the shock which occurs following a scalding burn. The shock-producing technic consists of immersing the entire body surface, except for the head and neck, of etherized rats and mice for definite intervals of time into a water-bath set at scalding temperatures. Therapeutic activity is evaluated by repetitive testing, where the percentage of survival and the average survival period of a group of treated animals is compared to suitable control groups, scalded and observed under identical conditions. This method allows objective control of the degree of thermal injury and thereby insures that the animals within groups are damaged to the same extent. Since the technic is simple and fast, the method permits the traumatization of large numbers of animals in any given experiment under identical conditions of room temperature, humidity, etc. By housing and feeding all rats or mice in any given experiment under identical laboratory conditions, factors such as the preexperimental nutritional regime, tissue hydration, etc., are adequately controlled. Finally, the features which permit the employment of large groups of animals, allow the results ob-

1 Aided by grants from the Beaumont Trust Fund, The Martha Kirschner Haft Memorial Fund, and Mr. Tom May, Mr. Walter Kirschner, Mr. Morton May, and Mr. Fred Glick. A preliminary report of this work has appeared in the J.A.M.A., 1943, 122, 720. tained to be statistically evaluated for their significance. A similar scalding method has recently been described (1).

\section{METHOD}

The water-bath used in these experiments was a 10 gallon jug, in which the water was mixed by a stirring motor. The bath temperature was regulated by a thermostat so that it varied no more than $\pm 0.5^{\circ} \mathrm{C}$. After the bath had been set at the desired temperature, rats or mice were rapidly anesthetized with ether. The loose skin in the occipital region was then grasped with a hemostat, and the animal was plunged into the scalding water in such a manner that only the head and neck remained above water. After the desired interval of immersion, the animal was withdrawn and placed in a bucket containing sawdust to permit partial drying. The rate of traumatizing animals by this scalding procedure may be increased several-fold if animals are anesthetized in groups and 2 or more animals are simultaneously scalded. Using these procedures, 2 people may scald as many as 6 rats or mice every minute. The duration of exposure to the scalding temperature was generally 10 to 15 seconds. The accuracy of these immersion periods was approximately \pm 0.5 second. These intervals of exposure appeared to be optimal, since decrease in duration to 5 seconds decreased the accuracy of the exposure, while with the immersion periods above 20 seconds it was observed that animals tended to awaken from anesthesia and began to struggle. Ether anesthesia was used in preference to non-volatile anesthetics, such as avertin and nembutal, for the reason that we have found that avertinized and nembutalized animals which had been scalded awakened from anesthesia very slowly. Following the start of the experiment, food and water were withheld from the animals.

Survival observations after thermal injury were conducted over a 48-hour period, and all experiments were terminated at that time to prevent the effects of infection and other secondary disturbances, which later become operative, from influencing mortality. The groups were observed at regular intervals, the dead animals being removed and the time of death noted. A small percentage of the animals died within the first 30-minute period following scalding and these animals were discarded from the experimental groups because it seemed unlikely that death was due to secondary shock. All animals still alive when the experiment was terminated, were arbitrarily assigned a survival period of $\mathbf{4 8}$ hours.

Upon awakening from anesthesia, scalded animals show characteristic changes before dying. Immediately follow- 
ing scalding, there is an apparent recovery; however, increased irritability and decreased spontaneous activity are evident. Later, the skin becomes cold, dyspnea develops, the animals become profoundly asthenic, and eventually death occurs. A short time after immersion, the tail and extremities become edematous, and if the animal survives the first 24 hours, dry gangrene of the edematous peripheral extremities usually is evident.

\section{PATHOLOGICAL CHANGES}

Post mortem examination of animals dying in shock as the result of thermal injury revealed the following macroscopic findings: pulmonary congestion was regularly observed, visceral congestion was usually found, and hemorrhagic adrenals and gross hematuria were irregularly seen. Those findings which appeared seemed to be related to the period of survival following scalding, becoming more frequent as the survival time was increased. Thus, animals dying immediately or soon after scalding, while exhibiting pulmonary congestion, rarely showed visceral congestion, adrenal changes, or gross hematuria. However, as the period of survival increased, the frequency of visceral congestion, hematuria, and adrenal damage likewise progressively increased. Microscopic examination revealed congestion in lung, intestine, kidney, adrenals, and other organs.

\section{EFFECT OF THERMAL INJURY ON BLOOD CON-} CENTRATION AND SKIN TEMPERATURE

We have found that a significant degree of hemoconcentration is consistently evident following scalding. It has been shown that mice which have been subjected to scalding likewise exhibit hemoconcentration (1). Figure 1 illustrates typical findings on changes in skin temperature following scalding. It will be seen that decrease in blood flow to the skin accompanies the clinical appearance of shock in animals subjected to a scalding burn.

\section{INFLUENCE OF SEX, STRAIN, BODY WEIGHT}

The rats and mice used in these studies, obtained from different breeders and representing various strains, were fed Purina fox chow and water $a d l i b$. until the time of experimentation. Recognizing that animals from different strains might exhibit varying degrees of resistance to thermal injury, all experiments were designed in such a manner that animals of a given weight range from the same source were selected at random to form the various groups. The mice used in these studies weighed between 18 and 25 grams and the rats varied from 200 to $\mathbf{4 0 0}$ grams.

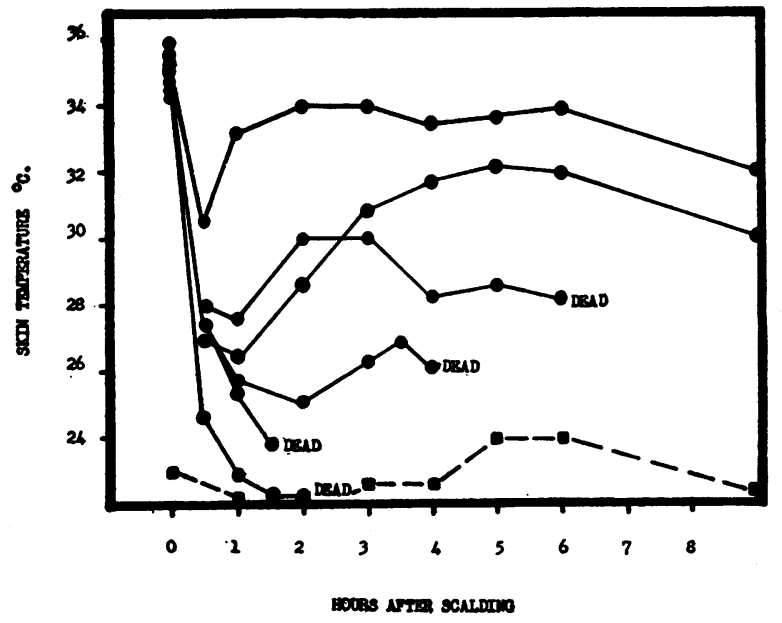

Fig. 1. The Effect of Scalding Mice Upon SKIN TEMPERATURE

(๑- ๑) represents individual curves of mice showing representative examples; $(\boldsymbol{\square}-\boldsymbol{\square})$ room temperature.

The variation of body weight of rats within groups in a single experiment, however, was no more than \pm 25 grams. It may be of interest to mention that with rats, and possibly mice, it appeared that smaller animals died more rapidly than larger animals following comparable thermal injury.

To check on the possible effects of sex difference upon resistance to thermal injury, animals derived from the same source and in the same weight range, were divided into groups on the basis of sex and scalded under identical conditions. The following data are from a representative experiment on this point: of 72 male mice scalded at $60^{\circ} \mathrm{C}$. for 10 seconds, 36 per cent survived and the average survival time was 31.4 hours, while 54 females had a percentage of survival of 43 per cent, and the average survival time was 34.0 hours. These differences are not large, and as will be shown later, are not significant. Similar experiments with rats likewise have demonstrated that the sex of the animal has little influence upon the survival time following scalding.

\section{EFFECT OF VARIATION OF IMMERSION DURATION AT VARIOUS SCALDING TEMPERATURES UPON THE SURVIVAL TIME OF RATS AND MICE}

$A$ priori, it would appear that the degree of thermal injury inflicted by scalding, as evidenced 
by time mortality curves, should be a function of the duration of exposure and of the scalding temperature. It may be expected that if the thermal injury is too slight, an insufficient number of control animals would die and therapeutic activity would not be measurable. On the other hand, if the thermal injury be progressively increased, it might be expected that a point would be reached where the damaged animals would die rapidly, irrespective of treatment. It would therefore appear that a degree of trauma, intermediate between these extremes, would represent the desirable conditions for evaluating therapeutic activity. Experiments were performed to find the minimal degree of trauma which would kill most of our animals in a 48-hour period. Two experiments are shown in Figures $2 a$ and $2 \mathrm{~b}$, one with rats, the other with mice, which

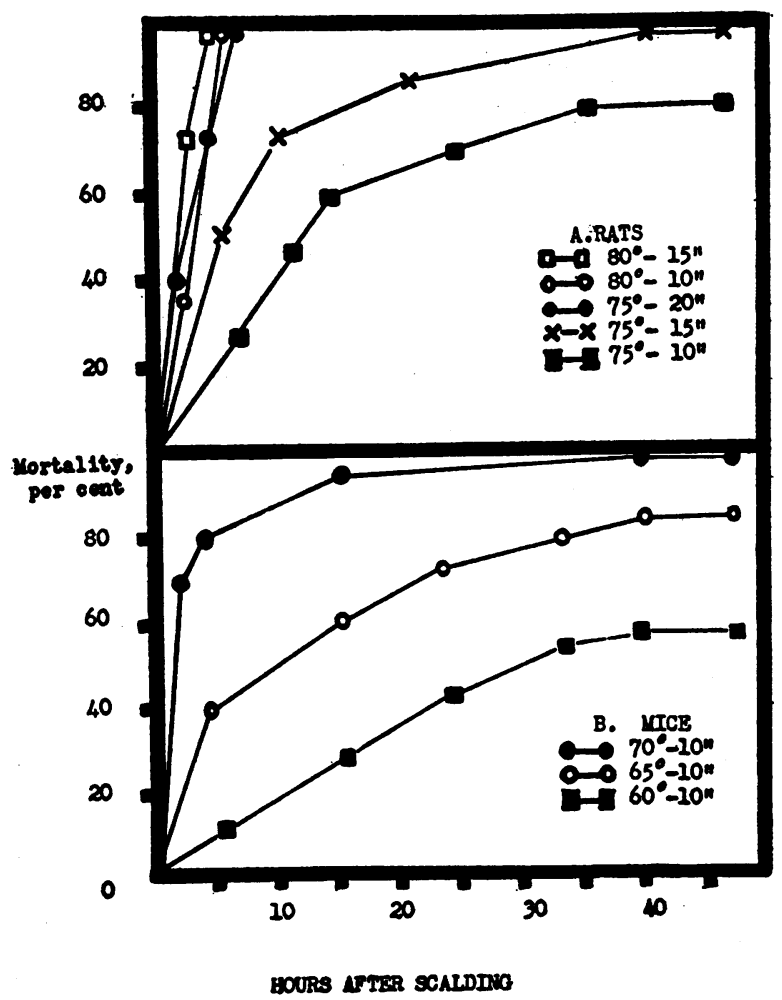

Fig. 2. Shows the Effect of Varying the Scalding TEMPERATURE OR THE IMMERSION TIME UPON TIME Mortality Curves

Each curve represents 50 animals. It will be seen that the higher the temperature or the longer the period of immersion, the greater the rate of mortality. The significance of these curves as regards absolute values is limited because only one experiment was performed. illustrate the method of determining the optimal conditions of exposure and temperature for evaluating therapeutic activity. It is clear from these data that the rate of mortality is a function of the exposure duration and of the bath temperature, and may be adjusted to desired levels by alteration of the scalding conditions.

The conditions for scalding our animals which have generally proved satisfactory for evaluating therapeutic activity were an immersion duration of 10 seconds at $65^{\circ} \mathrm{C}$. for mice weighing approximately 20 grams; and 10 or 15 seconds at $75^{\circ} \mathrm{C}$. for rats weighing approximately 200 grams. It should be emphasized that the conditions which proved satisfactory for evaluating therapeutic activity in this laboratory may vary for other strains of animals or under different laboratory conditions.

\section{VARIABILITY INHERENT IN THE SCALDING METHOD}

The variations in response which exist with all shock-producing procedures has been emphasized (2). The scalding procedure described provides a statistical approach to the problem of overcoming the factor of individual animal variation in that the response of large groups of animals to standardized thermal injury is studied under identical conditions. To determine the variations inherent in the scalding technic, animals of the same strain and weight range were divided into 5 or more groups of 20 to 30 animals per group by random selection. The animals in each group received no treatment and were scalded and observed under identical conditions. The results obtained in 2 experiments using rats and in 2 experiments with mice are illustrated in Figures $3 a, b, c$, and $d$. It will be seen that considerable variation between presumably identical groups consistently occurs. Using either the average troup survival time or the percentage of survival of the groups as a criterion for the response to thermal injury, it is evident that the variability between the extremes may be as great as or greater than 100 per cent. Differences of this degree, using 20 or $\mathbf{3 0}$ animals per group obtained by random selection, can be calculated by statistical methods to be significant. This discrepancy between the actual and the expected degree of variability, indicates that there is some 


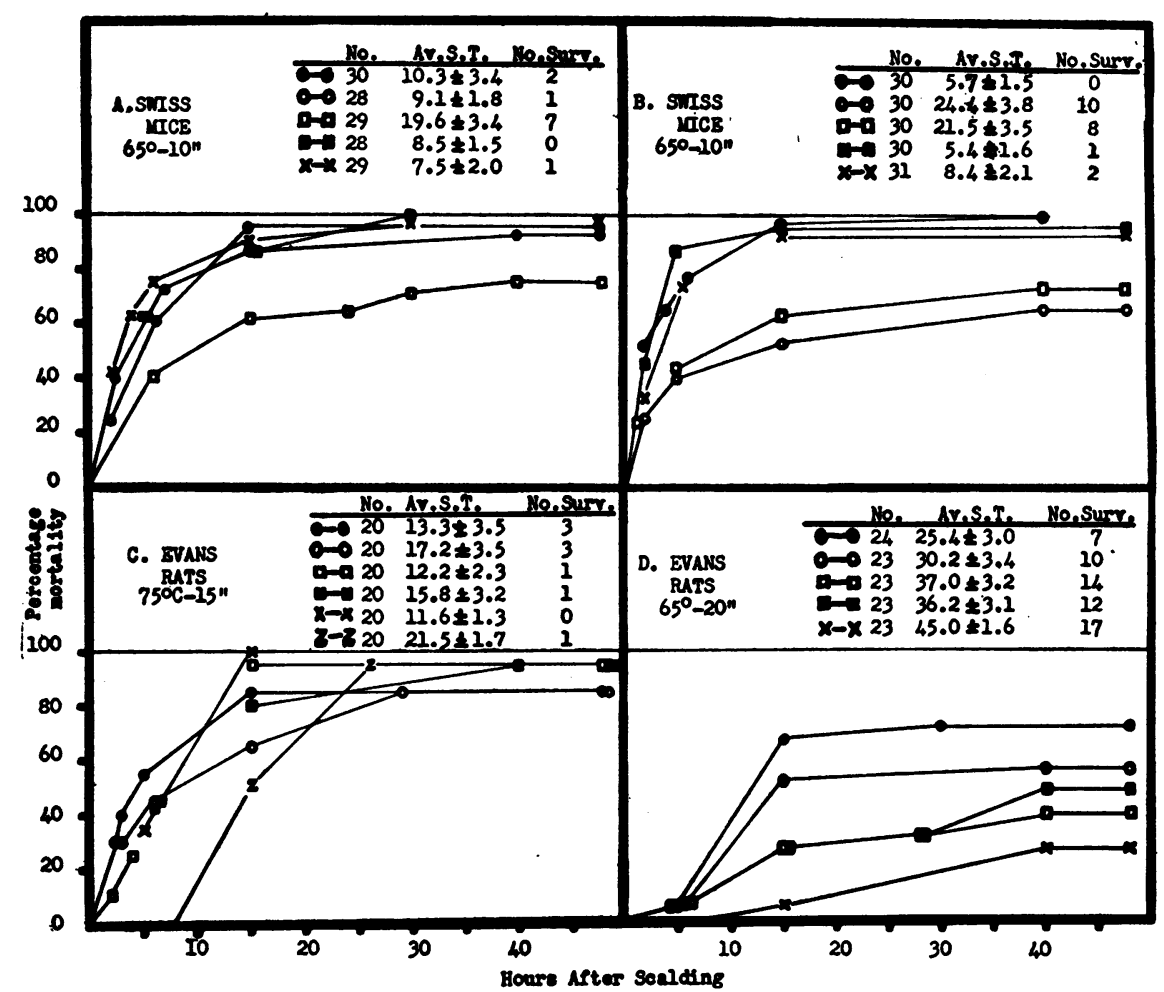

Fig. 3. Four Experiments, 2 with Mice, 2 with Rats, Which Illustrate the Variability of Groups of Untreated, Presumably Identical Animals, Scalded UNDER IDENTICAL CONDITIONS

Each curve represents a group consisting of 20 to 31 animals. It may be seen that considerable variation exists both in the average survival time (Av. S. T.) and in the number surviving (No. Surv.). The standard error is shown following the Av. S. T., and it may be observed that these differences can be calculated to be statistically significant.

unknown variable operative in the experiment, which is capable of significantly modifying the response to standardized trauma.

Recognizing the limitations imposed by the variability inherent in the scalding procedure, it would appear that the evaluation of therapeutic activity is measurable only with the conditions of repeated testing. Let us consider the type of effects which would be obtained with active and inactive anti-shock agents:

(a) If a substance does not possess anti-shock activity, in a sufficient number of tests the results should depend only upon chance; thus, it is possible in a single trial to obtain positive results, which appear to be statistically significant, using as many as $\mathbf{3 0}$ animals to a group. Likewise, apparently deleterious effects may be obtained with inert material. In many instances, the control and treated groups will be identical. This may serve to explain why statistically significant positive therapeutic effects can be obtained with an agent possessing no anti-shock activity, and is possibly an explanation for certain differences of opinion regarding the antishock activity of certain agents. (b) If the agent under test has the activity of increasing average survival time only about $\mathbf{1 0 0}$ per cent, which is approximately the range of variation, on repeated testing, definite positive effects should be obtained in some cases; in other tests, the treated group should show the same response as the control groups, but in no instances should the agent be worse than the controls. (c) If the agent has powerful anti-shock activity (assume 
TABLE I

Effect of treatment with 15 unit liver on the average survival time and percentage survival of mice subjected to scalding, arranged according to survival time of the control groups

\begin{tabular}{|c|c|c|c|c|c|c|c|c|}
\hline \multicolumn{4}{|c|}{ Controls } & \multicolumn{5}{|c|}{ Liver } \\
\hline Exp. No. & Number mice & $\begin{array}{c}\text { Average } \\
\text { survival } \\
\text { time }\end{array}$ & $\begin{array}{l}\text { Number } \\
\text { survived }\end{array}$ & Number mice & $\begin{array}{c}\text { Average } \\
\text { survival } \\
\text { time }\end{array}$ & $\begin{array}{l}\text { Number } \\
\text { survived }\end{array}$ & $\begin{array}{l}\text { Increase in } \\
\text { average sur- } \\
\text { vival time }\end{array}$ & $\begin{array}{c}\text { Increase } \\
\text { in } \\
\text { survived }\end{array}$ \\
\hline & & hours & & & hours & & per cent & per cent \\
\hline
\end{tabular}

AVERAGE SURVIVAL TIME CONTROL GROUPS LESS THAN 5 HOURS

\begin{tabular}{|c|c|c|c|c|c|c|c|c|}
\hline $\begin{array}{l}1 \\
2 \\
3 \\
4\end{array}$ & $\begin{array}{l}26 \\
41 \\
36 \\
32\end{array}$ & $\begin{array}{l}2.3 \\
3.8 \\
4.1 \\
4.1\end{array}$ & $\begin{array}{l}0 \\
0 \\
0 \\
0\end{array}$ & $\begin{array}{l}32 \\
36 \\
31 \\
33\end{array}$ & $\begin{array}{r}13.1 \\
4.7 \\
3.7 \\
10.7\end{array}$ & $\begin{array}{l}0 \\
2 \\
0 \\
3\end{array}$ & $\begin{array}{r}+470 \\
+\quad 23 \\
-\quad 9 \\
+161\end{array}$ & $\begin{array}{c}0 \\
+5.5 \\
0 \\
+9.1\end{array}$ \\
\hline
\end{tabular}

AVERAGE SURVIVAL TIME CONTROL GROUPS 5.0 TO 13.0 HOURS

\begin{tabular}{|c|c|c|c|c|c|c|c|c|}
\hline $\begin{array}{r}5 \\
6 \\
7 \\
8 \\
9 \\
10 \\
11 \\
12 \\
13 \\
14 \\
15 \\
16 \\
17 \\
18 \\
19 \\
20\end{array}$ & $\begin{array}{l}33 \\
30 \\
30 \\
24 \\
31 \\
19 \\
23 \\
33 \\
37 \\
25 \\
34 \\
27 \\
27 \\
36 \\
20 \\
30\end{array}$ & $\begin{array}{r}5.2 \\
5.7 \\
6.6 \\
7.0 \\
7.7 \\
8.0 \\
8.3 \\
8.6 \\
8.7 \\
9.4 \\
10.8 \\
11.4 \\
11.5 \\
11.9 \\
12.5 \\
12.5\end{array}$ & $\begin{array}{l}0 \\
0 \\
2 \\
0 \\
0 \\
1 \\
1 \\
3 \\
0 \\
4 \\
3 \\
0 \\
0 \\
1 \\
0 \\
4\end{array}$ & $\begin{array}{l}27 \\
29 \\
28 \\
23 \\
28 \\
25 \\
25 \\
34 \\
40 \\
29 \\
34 \\
25 \\
30 \\
35 \\
20 \\
28\end{array}$ & $\begin{array}{r}27.5 \\
14.8 \\
9.2 \\
16.4 \\
5.4 \\
29.6 \\
21.9 \\
25.9 \\
39.8 \\
20.0 \\
21.9 \\
28.2 \\
33.7 \\
16.5 \\
42.0 \\
29.6\end{array}$ & $\begin{array}{r}6 \\
13 \\
3 \\
11 \\
0 \\
10 \\
7 \\
14 \\
25 \\
22 \\
11 \\
11 \\
17 \\
6 \\
15 \\
9\end{array}$ & $\begin{array}{r}+430 \\
+160 \\
+39 \\
+134 \\
+30 \\
+270 \\
+158 \\
+201 \\
+358 \\
+113 \\
+103 \\
+147 \\
+193 \\
+39 \\
+236 \\
+137\end{array}$ & $\begin{array}{r}+22 \\
+45 \\
+4 \\
+48 \\
0 \\
+35 \\
+24 \\
+32 \\
+63 \\
+60 \\
+23 \\
+44 \\
+57 \\
+14 \\
+75 \\
+19\end{array}$ \\
\hline
\end{tabular}

AVERAGE SURVIVAL TIME CONTROL GROUPS 13 TO 20 HOURS

\begin{tabular}{|c|c|c|c|c|c|c|c|c|}
\hline $\begin{array}{l}21 \\
22 \\
23 \\
24 \\
25 \\
26 \\
27 \\
28 \\
29 \\
30\end{array}$ & $\begin{array}{l}21 \\
16 \\
27 \\
41 \\
29 \\
35 \\
33 \\
40 \\
33 \\
40\end{array}$ & $\begin{array}{l}13.4 \\
14.3 \\
14.9 \\
15.2 \\
15.6 \\
16.3 \\
18.2 \\
19.7 \\
19.6 \\
19.9\end{array}$ & $\begin{array}{r}0 \\
0 \\
0 \\
2 \\
3 \\
5 \\
7 \\
6 \\
10 \\
8\end{array}$ & $\begin{array}{l}20 \\
19 \\
28 \\
40 \\
30 \\
33 \\
35 \\
38 \\
32 \\
39\end{array}$ & $\begin{array}{l}25.0 \\
25.0 \\
23.2 \\
33.0 \\
26.6 \\
28.0 \\
21.3 \\
33.2 \\
30.6 \\
27.4\end{array}$ & $\begin{array}{r}3 \\
5 \\
0 \\
14 \\
10 \\
16 \\
11 \\
18 \\
16 \\
19\end{array}$ & $\begin{array}{r}+87 \\
+75 \\
+36 \\
+117 \\
+70 \\
+42 \\
+17 \\
+69 \\
+36 \\
+38\end{array}$ & $\begin{array}{r}+15 \\
+26 \\
0 \\
+30 \\
+23 \\
+39 \\
+10 \\
+32 \\
+20 \\
+29\end{array}$ \\
\hline
\end{tabular}

AVERAge SURVIVAL TIME CONTROL GROUPS ABOVE 20 HOURS

\begin{tabular}{|c|c|c|c|c|c|c|c|c|}
\hline $\begin{array}{l}31 \\
32 \\
33 \\
34 \\
35 \\
36 \\
37 \\
38 \\
39\end{array}$ & $\begin{array}{l}30 \\
42 \\
27 \\
39 \\
44 \\
36 \\
29 \\
30 \\
30\end{array}$ & $\begin{array}{l}21.0 \\
21.8 \\
22.0 \\
23.7 \\
24.0 \\
31.0 \\
38.0 \\
39.1 \\
42.6\end{array}$ & $\begin{array}{r}8 \\
12 \\
4 \\
7 \\
16 \\
15 \\
20 \\
16 \\
24\end{array}$ & $\begin{array}{l}30 \\
39 \\
30 \\
38 \\
39 \\
33 \\
31 \\
34 \\
30\end{array}$ & $\begin{array}{l}27.9 \\
32.4 \\
39.0 \\
28.8 \\
32.0 \\
29.5 \\
37.4 \\
35.1 \\
43.7\end{array}$ & $\begin{array}{l}14 \\
13 \\
19 \\
13 \\
19 \\
15 \\
18 \\
17 \\
26\end{array}$ & $\begin{array}{r}+42 \\
+\quad 49 \\
+\quad 77 \\
+\quad 21 \\
+\quad 33 \\
-\quad 5 \\
-\quad 2 \\
-\quad 11 \\
+\quad 3\end{array}$ & $\begin{array}{r}+20 \\
+6 \\
+48 \\
+16 \\
+13 \\
+4 \\
-10 \\
-3 \\
+7\end{array}$ \\
\hline
\end{tabular}


that it increases the average survival time $\mathbf{5 0 0}$ per cent), this activity would be consistently evident despite a variation of 100 per cent.

\section{RESULTS}

\section{Effect of liver extract}

In the course of preliminary testing, it was observed that 3 commercial liver extracts, which contain anti-anemia activity, all appeared to increase the survival time of animals subjected to scalding. Extensive testing of one of these extracts was undertaken to establish whether or not this action of liver extract was reproducible and significant. In these experiments, mice were the test animals; the liver extract (Lederle), containing 15 injectable U.S.P. units of anti-anemia activity per $\mathrm{ml}$. in 0.5 per cent phenol, was injected intraperitoneally in a dosage of $1.0 \mathrm{ml}$. per 100 grams body weight, approximately 0.5 hour prior to scalding. As a control for the fluid administered, groups of mice were injected with equivalent amounts of either physiological saline or 0.5 per cent phenol, at the same time interval prior to experimentation. In some experiments, a second control group, which received no treatment, was used in addition to the fluid control.

Table I illustrates the results of 39 experiments, using 2,426 mice, where the effect of liver on the average survival time and on the percentage survival is shown. The table has been subdivided arbitrarily into 4 divisions corresponding to the degree of thermal injury as evaluated by the average survival time of the control group. Figure 4a shows the effect of liver treatment upon the survival time and upon the percentage survival, at these varying ranges of thermal injury. It will be seen that liver has a tendency to increase the average survival time and to decrease the percentage mortality under all conditions of thermal injury. However, it is clear that this anti-burn shock activity of liver is best evident when the conditions of thermal injury are such that the control groups die with an average survival time varying from 5.0 to 20.0 hours, since the activity decreases when the conditions of thermal injury are either decreased or increased so that the significance of the effects at both extremes is questionable.

Figure $4 \mathrm{~b}$ shows that the control solutions, saline and 0.5 per cent phenol, given in amounts

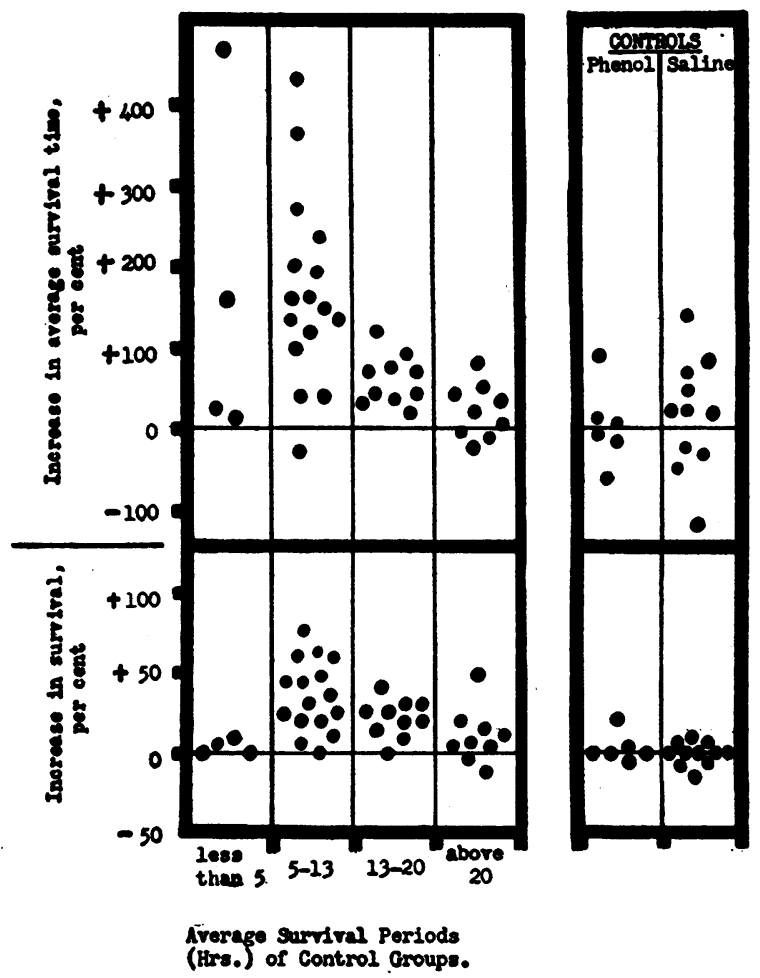

Fig. 4A. The Effect of 15 unit Liver on the Average Survival Time and on the Percentage Surviving as Compared to the fluid Control, at Various RANGes OF TherMal InJURY

Each dot represents the response of a group comprising 19 to $\mathbf{4 0}$ animals, the total number of mice employed in this study being 2426 mice. It can be seen that in ranges where the control average survival periods fell between 5 and 13 , and 13 and 20 hours, that liver treatment increased the percentage surviving and the mean survival time in most instances. However, the anti-shock activity of liver is not marked, if the degree of thermal injury is too great or too slight.

Fig. 4b. The Effect of the Control Solutions, Saline and 0.5 per cent Phenol, as Compared to No TreatMent

It will be seen that either solution is an adequate control. These data demonstrate, as does Fig. 4a, the range of variations of control groups.

equivalent to 1 per cent of the body weight, 0.5 hour prior to trauma, had no significant effect and it is further evident that either solution would serve equally as well as a fluid control for liver extract.

The question naturally arises as to why liver shows significant activity in certain ranges of thermal injury, and is without marked effect when the degree of trauma is increased or de- 
creased. As has been previously mentioned, it was predicted that there would be conditions of thermal injury which are unsatisfactory for evaluation of anti-shock activity. Thus, when the dégree of trauma is too great, it was mentioned that the animals may die rapidly irrespective of treatment and this situation appears to have occurred in those experiments where the average survival time of the controls was less than 5 hours. Under conditions wherein the degree of trauma was relatively slight, the relative ineffectiveness of liver may be due to the fact that an insufficient number of control animals died, or it may be that the in vivo concentration of the liver principle becomes depleted early in the course of the experiment so that it cannot effectively combat the deaths that occur later.

\section{Effect of 5 per cent saline and of liver extract plus 5 per cent saline}

\section{A. Effect of large volumes of saline}

As early as 1926, it was observed that the chloride of whole blood and plasma was significantly lowered following burns (3), and large amounts of saline were administered as one aspect of the treatment of burns with good results (4). We have found that the intraperitoneal administration of 0.9 per cent sodium chloride given, in amounts equivalent to 5 or 10 per cent of the body weight, to mice and rats after scalding, significantly decreased mortality. This effect has been independently observed (1) and it was shown that the sodium salts of various acids, given in isomolar concentrations, are as effective as sodium chloride solutions in preventing death following a scalding burn (5). It was further found in this laboratory that saline given in amount equivalent to 5 per cent of the body weight 0.5 hour prior to scalding decreased mortality. (Table II).

\section{B. Effect of liver plus saline as compared to saline alone}

It was of interest to determine whether combined pretreatment with liver plus saline was superior to pretreatment with salt solution alone. Using mice, 3 experiments were performed in the following manner: Three groups containing at least 30 mice per-group received one of the following treatments; (a) physiological saline, 5 per cent of the body weight, administered intraperitoneally approximately 0.5 hour prior to trauma; (b) 15 unit liver extract in saline, intraperitoneally, 0.5 hour before scalding, in amounts so that the dosage of liver extract was $1.0 \mathrm{ml}$. per 100 grams of body weight and the volume of salt solution was 5 per cent of the body weight; and $(c)$ a control, receiving no treatment. The composite results of the 3 experiments are shown graphically in Figure 5. It will be seen that saline increased the survival time 238 per cent and the percentage surviving 22.3 per cent over the control non-treated group. Liver plus saline treatment increased the average survival time 352 per cent and the percentage surviving 35.8 per cent over the non-treated control group. This represents an increase of 144 per cent in

TABLE II

The effect of $5 \mathrm{ml}$. saline per 100 grams of body weight, given intraperitoneally 0.5 hour prior to scalding, in mice and rats at $65^{\circ}$ for 10 seconds

\begin{tabular}{|c|c|c|c|c|c|c|c|c|c|}
\hline \multirow{2}{*}{$\begin{array}{c}\text { Test } \\
\text { animals }\end{array}$} & \multirow{2}{*}{$\begin{array}{l}\text { Exp. } \\
\text { No. }\end{array}$} & \multicolumn{3}{|c|}{ No treatment } & \multicolumn{3}{|c|}{ Saline } & \multirow{2}{*}{$\begin{array}{l}\text { Increase in } \\
\text { survival time }\end{array}$} & \multirow{2}{*}{$\begin{array}{l}\text { Increase in } \\
\text { survived }\end{array}$} \\
\hline & & $\begin{array}{l}\text { Number } \\
\text { animals }\end{array}$ & $\begin{array}{c}\text { Average } \\
\text { survival time }\end{array}$ & $\begin{array}{l}\text { Number } \\
\text { survived }\end{array}$ & $\begin{array}{l}\text { Number } \\
\text { animals }\end{array}$ & $\begin{array}{c}\text { Average } \\
\text { survival time }\end{array}$ & $\begin{array}{l}\text { Number } \\
\text { survived }\end{array}$ & & \\
\hline Mice & $\begin{array}{l}1 \\
2 \\
3 \\
4 \\
5 \\
6 \\
7\end{array}$ & $\begin{array}{l}25 \\
22 \\
20 \\
21 \\
66 \\
50 \\
30\end{array}$ & $\begin{array}{r}\text { hours } \\
5.7 \\
7.2 \\
14.8 \\
8.3 \\
9.3 \\
4.9 \\
2.9\end{array}$ & $\begin{array}{l}0 \\
0 \\
2 \\
1 \\
4 \\
0 \\
0\end{array}$ & $\begin{array}{l}20 \\
22 \\
20 \\
21 \\
64 \\
48 \\
29\end{array}$ & $\begin{array}{r}\text { howrs } \\
12.5 \\
7.5 \\
35.8 \\
17.3 \\
15.3 \\
27.7 \\
10.8\end{array}$ & $\begin{array}{r}1 \\
0 \\
5 \\
4 \\
10 \\
19 \\
5\end{array}$ & $\begin{array}{r}\text { per cent } \\
+120 \\
+\quad 4 \\
+142 \\
+108 \\
+65 \\
+455 \\
+272\end{array}$ & $\begin{array}{c}\text { per cent } \\
+\quad 5 \\
0 \\
+15 \\
+15 \\
+10 \\
+40 \\
+17\end{array}$ \\
\hline Rats & $\begin{array}{l}8 \\
9\end{array}$ & $\begin{array}{l}30 \\
35\end{array}$ & $\begin{array}{r}24.0 \\
3.2\end{array}$ & $\begin{array}{l}7 \\
0\end{array}$ & $\begin{array}{l}29 \\
35\end{array}$ & $\begin{array}{r}38.6 \\
7.0\end{array}$ & $\begin{array}{r}19 \\
1\end{array}$ & $\begin{array}{l}+61 \\
+119\end{array}$ & $\begin{array}{l}+43 \\
+3\end{array}$ \\
\hline
\end{tabular}




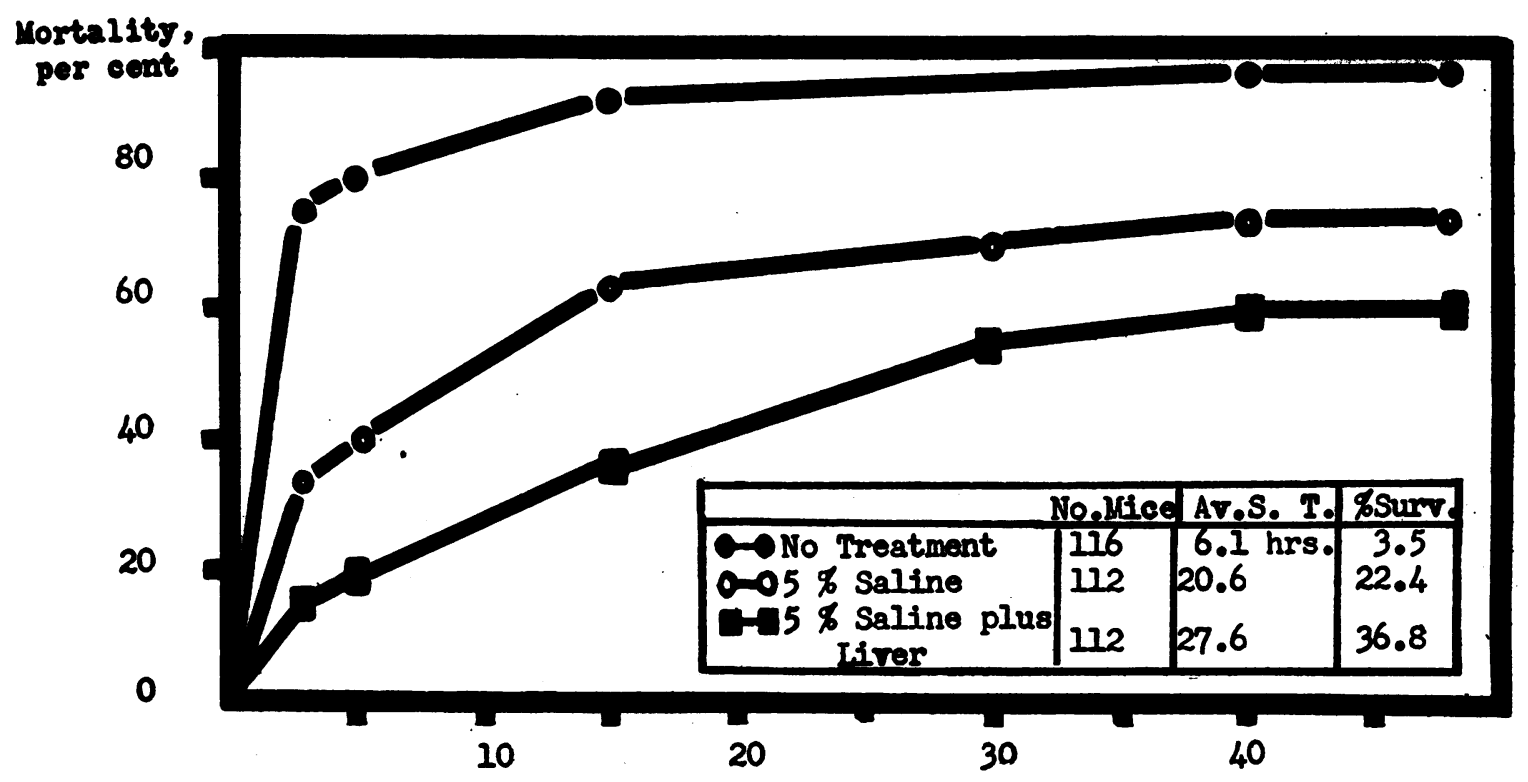

HOURS AFTER SCALDING.

Fig. 5. The Effect of Liver Plus 5 per cent Saline and of 5 per cent Saline Alone Upon Mice Subjected to Scalding at $70^{\circ}$ C. For $10^{\prime \prime}$

Each curve represents the composite results of 3 experiments, using a total of 112 to 116 animals per group. These data show that liver plus saline is superior to saline alone.

average survival time and a 13 per cent increase in the percentage of survival for the combined treatment. In these 3 experiments, the individual percentage differences in average survival time between liver plus saline as compared to saline alone over non-treated controls, was +260 per cent, +100 per cent, and +92 per cent, respectively.

Using rats as the test animals, 9 experiments of the following type were performed: rats were divided into 2 groups containing at least 15 animals per group; one group received liver extract subcutaneously 18 hours prior to experimentation, and at approximately 0.5 hour prior to scalding, both groups were intraperitoneally injected with 0.9 per cent $\mathrm{NaCl}$, in amounts equivalent to 5 per cent of the body weight and were then scalded under identical conditions. In these experiments, Lederle 15 unit liver extract was tested in 4 experiments, and in the 5 remaining tests, a Lilly liver extract containing 2 U.S.P. anti-anemia units per $\mathrm{ml}$. was employed. The dosage of liver extract used was $0.7 \mathrm{ml}$. per 100 grams of body weight for the 15 unit liver, and $0.8 \mathrm{ml}$. per 100 grams of body weight for the 2 unit liver. The results obtained are illustrated in Figure 6. It will be seen that in 9 trials, where the average survival time of the saline controls was less than 15 hours, liver plus saline treatment was consistently superior to saline alone.

\section{Is the anti-shock activity identical with the anti-anemia principle?}

The 15 unit liver extract, which has been shown in the previous sections to possess anti-shock activity contains the liver anti-anemia principle. It was, therefore, of interest to determine whether or not the activity against burn shock was due to the anti-anemia activity present in the extract. To answer this question, the anti-shock activity of liver extracts containing anti-anemia activity in a high degree of purification was determined. These purified anti-anemia extracts furnished us by Dr. Y. Subbarow of the Lederle Laboratories were prepared by methods previously described (6) which may be briefly summarized as follows: The activity in 15 unit liver was precipitated as 


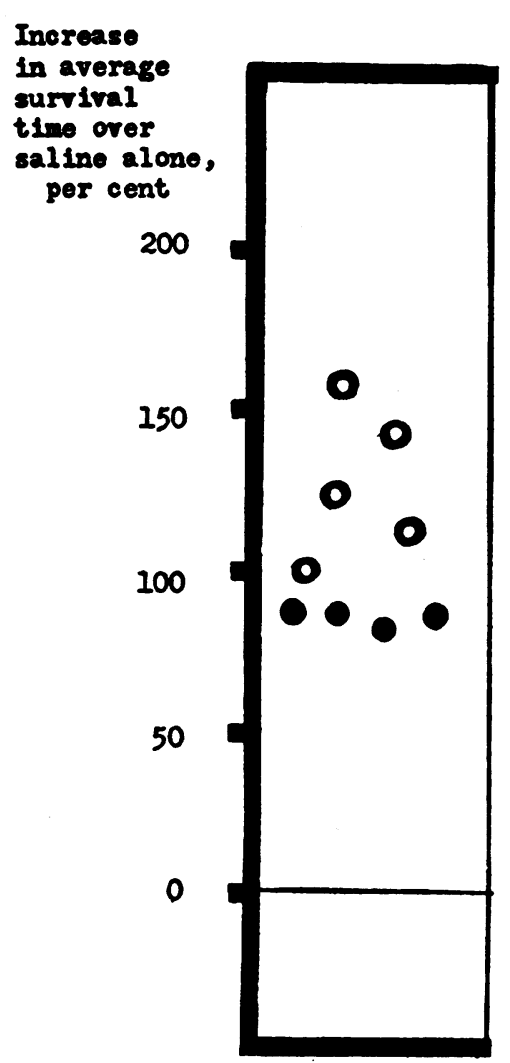

Fig. 6. The Effect of Liver Plus Saline as Compared to Saline Alone in Rats Scalded at $85^{\circ}$ for 15 SECONDS

Circles represent 2 unit liver extract; black dots, 15 unit liver. Each dot or circle represents 15 to 20 rats.

a Reinecke salt; the reagent was removed; the anti-anemia activity was absorbed by charcoal and subsequently eluted. At this stage, the material, designated in this discussion as the charcoal absorbant, contains one U.S.P. antianemia unit per mgm. On treatment of the charcoal absorbant with 10 volumes of $1: 1$ acetone-ether, a precipitate, containing all of the anti-anemia activity, is obtained.

The anti-shock activity of both extracts containing an amount of anti-anemia principle equivalent to 15 unit liver, was evaluated by comparing the survival of groups injected with these fractions, with the results obtained with 15 unit liver and a saline control simultaneously performed. Seven experiments of this type were performed and the results are shown in Figure 7, where the percentage increase in average survival time over the control produced by 15 unit liver and the purified extracts is illustrated. It will be seen that while 15 unit liver is active, the purified extracts are consistently without significant activity. These data demonstrate that the anti-shock activity present in 15 unit liver is removed from the liver extracts by procedures which are used to purify anti-anemia activity. It is therefore concluded that the activity against burn shock present in liver extracts is not the anti-anemia principle.

\section{Solubility properties of the principle effective against burn shock}

In collaboration with Drs. Y. Subbarow and $\mathrm{N}$. Bohonos of the Lederle Laboratories, we are attempting to isolate the anti-burn shock principle in liver. Fractions of $\mathbf{1 5}$ unit liver prepared by Drs. Subbarow and Bohonos were tested in this laboratory in the manner described previ-

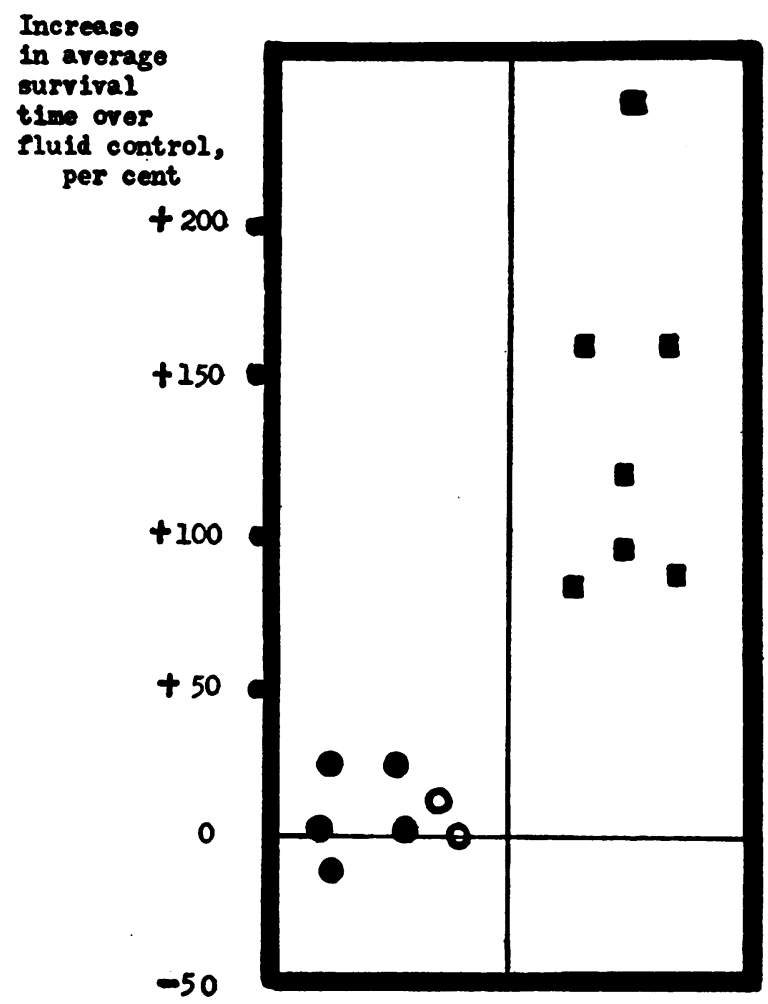

Fig. 7. The Anti-Shock Activity of Purified AntiANemia Liver Extracts as Compared to 15 unit Liver ExTract

Dots, charcoal absorbant; 0 circles, acetone-ether precipitate of charcoal absorbant; black squares, 15 unit liver. It may be seen that neither of the purified anti-anemia extracts possess anti-shock activity. 
ously for anti-anemia extracts. Figure 8 is a flow sheet which describes the chemical procedures employed to obtain the various fractions. Figure 9 illustrates the percentage increase in the average survival time over the fluid control group, produced by treatment with these fractions as compared to the 15 unit standard concurrently tested. The results may be summarized as follows: (a) On treatment of 15 unit liver with acetone, the activity is precipitated, little or no activity remaining in solution. (b) On treating this acetone precipitable fraction with ethanol, a precipitate is obtained which is active but possibly contains less activity than 15 unit standard. The ethanol solution appears to be inactive, but may contain slight activity. (c) Treatment of the acetone precipitable fraction of 15 unit liver with methanol gives rise to a precipitate which appears inactive as compared to the standard; however, slight activity may be present. The methanol solution likewise appears relatively inactive, but further testing would seem to be necessary before final conclusions are drawn on this point. (d) The absorbed fraction obtained by treatment of 15 unit liver with superfiltrol is active, although somewhat

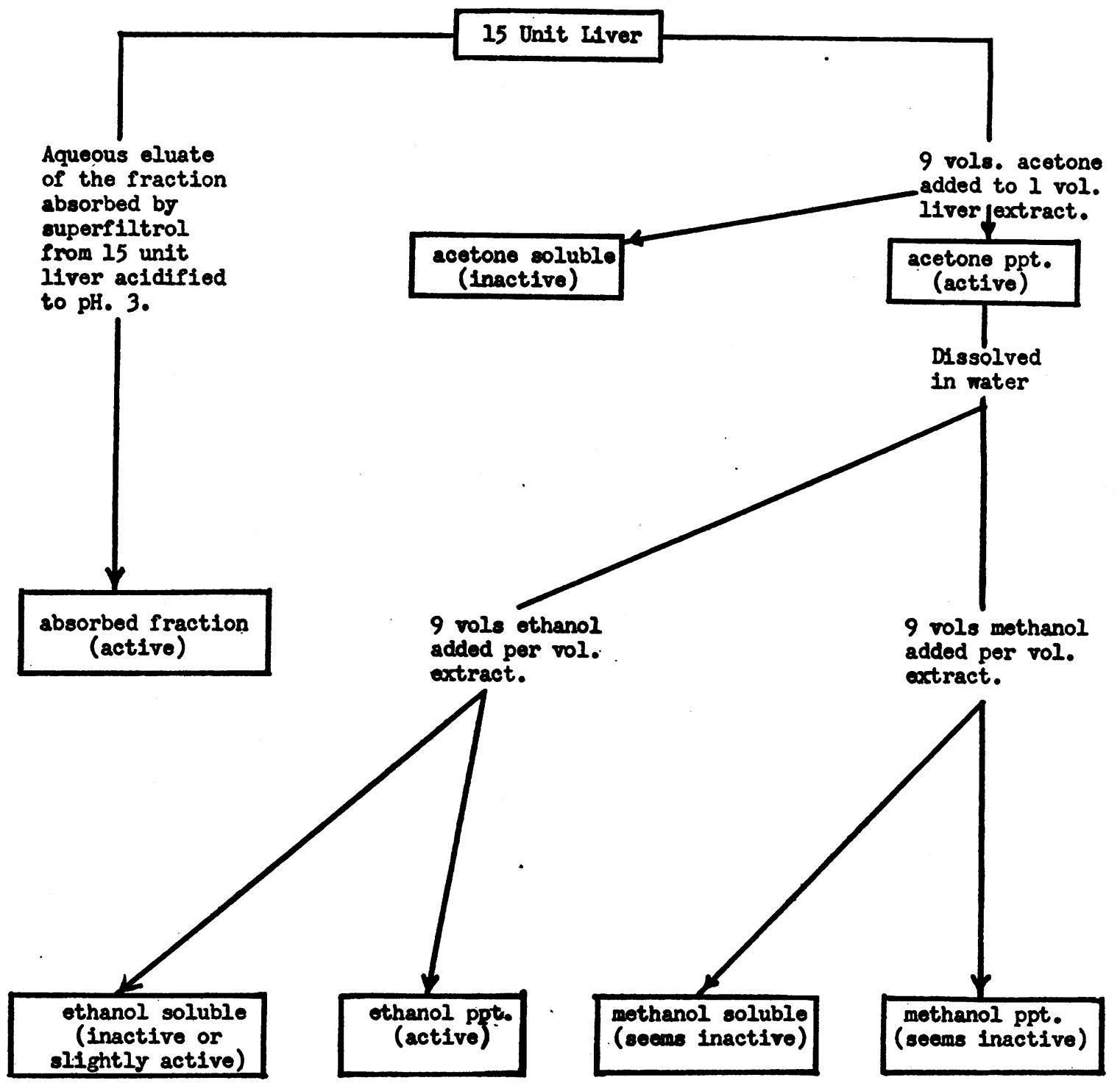

FIG. 8 


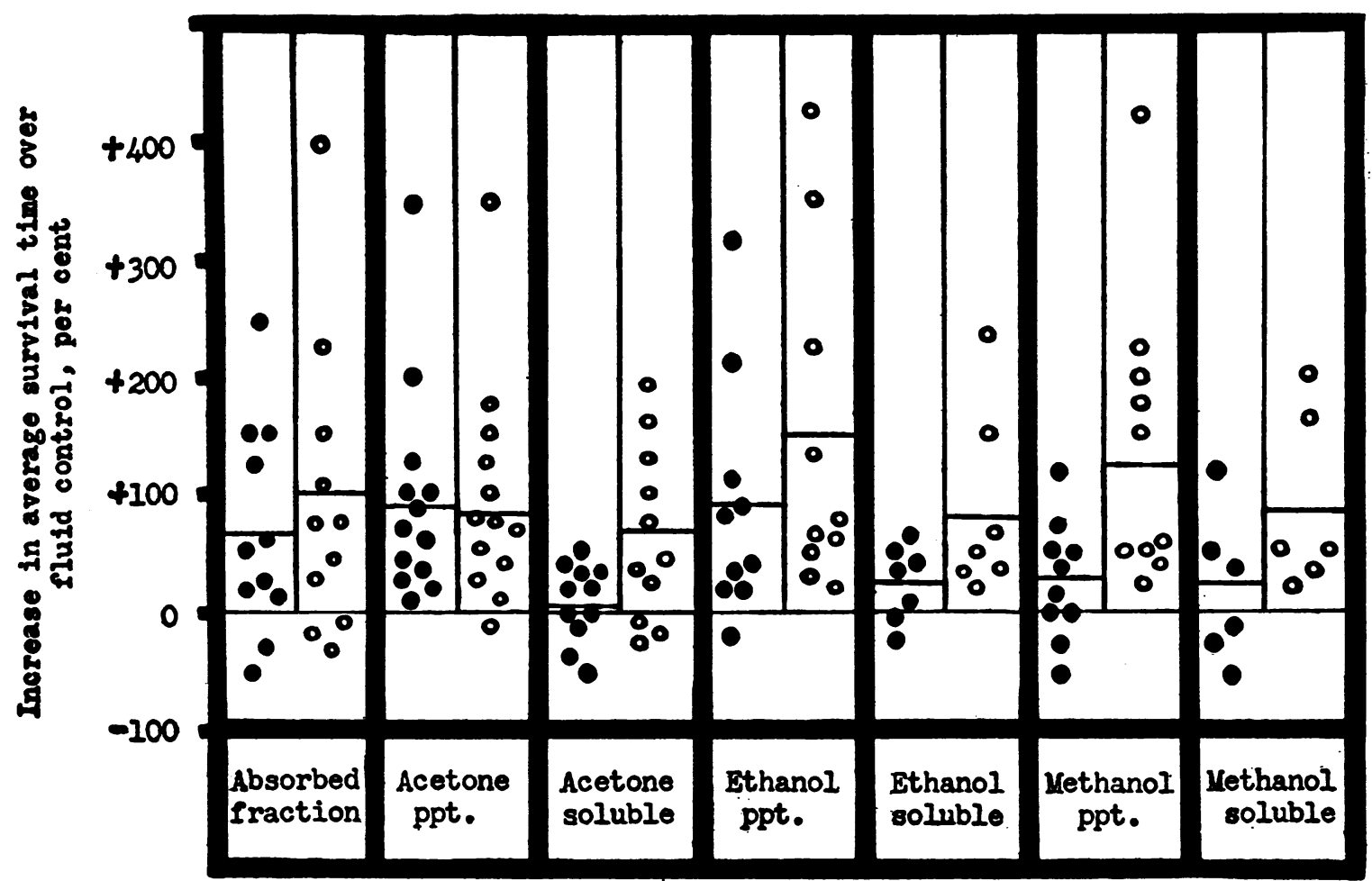

Fig. 9. Anti-Burn Shock Activity of Various fractions Derived from 15 unit Liver Extract

The black dots represent the fraction, the circles show the response with 15 unit liver. The cross lines represent the average of the responses. Each dot or circle is an individual experiment comprising 19 to 40 mice per group.

less than that obtained with the $\mathbf{1 5}$ unit standard. This difference, however, is not large and may not be significant. Discussion of the chemical nature of the anti-burn shock factor would appear to be premature, further work being necessary before the chemical nature of the activity can be characterized.

\section{DISCUSSION}

The evidence presented demonstrates the existence of an anti-burn shock activity in liver extracts. The mechanism by which the liver factor acts is as yet unknown, but it is possible that the liver principle either compensates for the fluid loss associated with burns, inhibits the activity of toxic substances believed by some to play a rôle in the etiology of shock, or corrects some other factor important for the production of shock. It will have been noted that the activity of liver extract against. burn shock was evident when the material was given prior to trauma. In terms of practical usefulness, it is important to know whether liver extract is effective when administered after the onset of shock. In this connection, we have found that the intraperitoneal injection of 15 unit liver at various time intervals after trauma while occasionally exhibiting activity, nevertheless appeared to be without significant effect. The finding that liver extract administered after scalding is usually ineffective in modifying survival, may possibly be due to the fact that large amounts of extraneous tissue constituents are present in all types of commercial liver extracts. It is likely that such impurities are deleterious to shocked animals, and thus may mask the therapeutic effects of the anti-shock activity. For this reason, experiments to determine the activity of liver extract administered after the onset of shock will be repeated when purified extracts of liver anti-burn shock activity are obtained. Questions related to dosage, route of administration, etc., have likewise been deferred until complicating constituents accompanying the antishock activity have been removed from the liver extracts. 
Thus far, it has only been shown that liver is effective against burn shock when given prior to thermal injury and whether it may prove to be useful in other types of shock has yet to be determined. We have found that liver appears to be ineffective in rats subjected to tourniquet shock or acute hemorrhage and acute septicemia in mice. Details of these studies will be subsequently published.

The significant variation between large groups of apparently homogeneous animals is a characteristic of the scalding method which warrants special mention, since it may be expected that this feature is common to all methods of evaluating anti-shock activity. While it was recognized that extreme individual variation might be expected in response to standardized thermal injury, it was thought that variations could be reduced to a minimum by using group response to identical thermal injury, where variable factors such as anesthesia, environmental conditions, sex, body weight, strain, nutritional status, and hydration, were adequately controlled. This expectation of insignificant variation with groups of 20 to 30 animals was not achieved, thus it was necessary to evaluate anti-shock activity on the basis of repetitive testing. In a number of instances, we have encountered substances which on repeated assay proved to be inactive, but which in the preliminary tests (using as many as 60 animals) seemed to possess significant antishock activity. It is clear that the attainment of an apparently significant response to a particular treatment in shock does not warrant the assumption that the same response will necessarily be obtained in the future. The question naturally arises as to whether the degree of variability encountered with the scalding technic applies to other methods of evaluating anti-shock activity. It would appear reasonable to suppose that methods which do not allow the employment of large groups. of homogeneous animals under identical conditions, would at least have the variability encountered with the scalding method, and most likely greater variability might be expected. This might indicate that the significance of results in shock therapy, which have not been repeatedly retested for consistency, is questionable, despite the fact that apparently significant responses were obtained in initial trials.
It may well be, that controversial reports concerning the anti-shock activity of certain agents are, in part, due to a lack of appreciation of the degree of variability inherent in shock-producing procedures.

\section{SUMMARY}

1. A new method for evaluating anti-burn shock activity is described, wherein activity is measured by studying the response of groups of animals on repetitive testing.

2. It has been demonstrated that statistically significant positive therapeutic effects may be obtained with inert materials having no antishock activity when as many as $\mathbf{3 0}$ animals are used in both the treated and control groups. This offers an explanation for the differences of opinion regarding the anti-shock activity of certain agents.

3. There is a principle in certain liver extracts which possesses the power of decreasing the mortality and increasing the survival time of animals subjected to burn shock.

4. This anti-burn shock factor, present in some commercial liver extracts, is not the antipernicious anemia principle.

5. Some of the solubility properties of the antiburn shock factor are described.

6. Intraperitoneal injection of 5 per cent of the body weight of saline is effective against shock.

7. Pre-treatment with liver extract plus saline is significantly more effective than salt solution alone.

\section{BIBLIOGRAPHY}

1. Rosenthal, S. M., Experimental chemotherapy of burns and shock. I. Methods. II. Effects of local therapy upon mortality from shock. Pub. Health Rep., 1942, 57, 1923.

2. Wiggers, C. J., Present status of shock problem. Physiol. Rev., 1942, 22, 74.

3. Davidson, E. C., Sodium chloride metabolism in cutaneous burns and its possible significance for a rational therapy. Arch. Surg., 1926, 13, 262.

4. Davidson, E. C., Tannic acid in treatment of burns. Surg., Gynec. and Obst., 1925, 41, 202.

5. Rosenthal, S. M., Experimental chemotherapy of burns and shock. III. Effects of systemic therapy on early mortality. Pub. Health Rep., 1943, 58, 513.

6. Jacobson, B. M., and Subbarow, Y., Studies of principle in liver effective in pernicious anemia. Recent advances in purification of active substances. J.A.M.A., 1941, 116, 367. 